\title{
EVALUATING SEIZURE ON FOUR BALL TESTER FOR RAPESEED OIL
}

\section{Traian Florian IONESCU, Liviu Cătălin ȘOLEA, Dionis GUGLEA, Constantin GEORGESCU, Lorena DELEANU}

\author{
“Dunarea de Jos” University, Galati, ROMANIA \\ lorena.deleanu@ugal.ro; traian.ionescu@ugal.ro
}

\begin{abstract}
This paper presents a tribological characterization in seizure regime for two lubricants (rapeseed oil and rapeseed oil additivated with $1 \%$ wt $\mathrm{TiO}_{2}$ ). Tests were done on a four-ball tester, in the load range at the tester shaft $500 \ldots 900 \mathrm{~N}$, in step of $50 \mathrm{~N}$, for 60 seconds and with a rotational speed of $1400 \mathrm{rpm}$ (equivalent to a sliding speed of $0.53 \mathrm{~m} / \mathrm{s}$ ). There were discussed the average value of friction coefficient, the wear scar diameter (WSD), the flash temperature parameter and several texture $3 D$ parameters. Till $600 \mathrm{~N}$, the influence of additivation is not obvious, the friction coefficient is lower for the neat oil, WSD is similar, but after this load, the slope for WSD is smaller for the additivated lubricant and for $900 \mathrm{~N}$, this parameter is also smaller. Sa seems to be quite insensitive to the load increase, but other parameters, like St has a significant increase, meaning two processes: additive is pressed on the surface and developed high local peaks or/and the adhesive and abrasive wear is more intense. FTP is almost the same at 900 $N$, but the additive makes this parameter to evolve with a plateau with low slope, meaning the additivated lubricant has a better behavior under high loads.
\end{abstract}

Keywords: rapeseed oil, $\mathrm{TiO}_{2}$, four ball tester, wear scar diameter, flesh temperature parameter (FTP)

\section{INTRODUCTION}

The EU is the world's largest producer of rapeseed and rapeseed products. In 2017/18, the forecast for planted area of EU rapeseed is $0.7 \%$ higher as compared to the previous year, reaching 6.6 million ha. Romania, Poland, Estonia, Czech Republic, Spain, Germany, Hungary and Lithuania report increased rapeseed acreage for 2017/18 [1]. Figure 1 presents the evolution of main vegetal oils in EU, rapeseed oil being the most important.

Rapeseed oil in industrial field (being approx. $72 \%$ of the total rapeseed oil production) is mainly used for biofuels, only approx. $10 \%$ of this having other industrial uses, including lubricants [1], [2].

$\mathrm{TiO}_{2}$ is mainly used as a white pigment in painting, cosmetics etc., the idea of using as lubricant additive being only recent supported by test results.

Ingole et al. [3] studied the influence of size particles of titanium dioxide in a mineral oil, on the lubricated E52100 bearing steel, using a reciprocating pin-on-disk apparatus. The additives were: nano-sized titanium dioxide $\left(\mathrm{TiO}_{2}\right.$-anatase), and commercially available $\mathrm{TiO}_{2}(\mathrm{P} 25)$ - a mixture of rutile and anatase phase. The friction and wear characteristics were examined at a constant applied load and rate of reciprocation. All concentrations of P25 increased the coefficient of friction, but the addition of $\mathrm{TiO}_{2}$ nanoparticles reduced the variability and stabilized the frictional behavior.

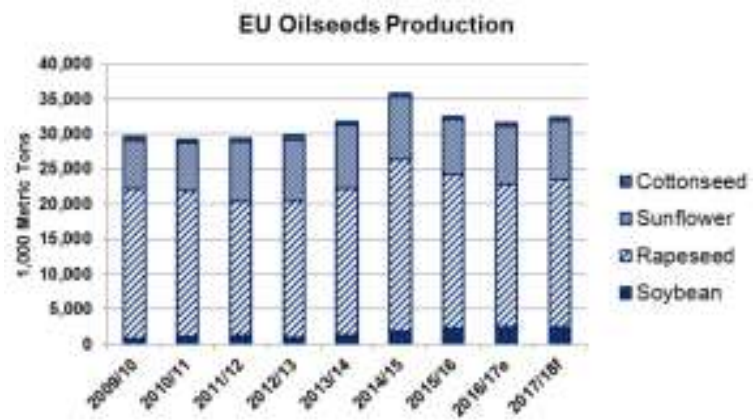

Fig. 1. The EU community production of oilseeds [1]

A recent study [4] reported results on rapeseed oil additivation with $\mathrm{CuO}(\approx 151.2 \mathrm{~nm}), \mathrm{CeO}_{2}(\approx 80 \mathrm{~nm})$ and polytetrafluoroethylene $(\approx 90.4 \mathrm{~nm})$, as nano additives, each in concentration of $0.1,0.25$ and $0.5 \%$ w/v, evaluated by a four-ball tester. The rapeseed oil 
was also epoxidized and its tribological behavior was compared to that of the neat oil, with the same additive concentrations. $\mathrm{CeO}_{2}$ and PTFE nanoadditives gave a significant reduction in the wear scar diameter, at the smallest concentration of $0.1 \% \mathrm{w} / \mathrm{v}$. In the extreme-pressure test, $0.5 \% \mathrm{w} / \mathrm{v}$ concentration was optimum for these nano additives, but PTFE particles shows no improvement. For $\mathrm{CuO}$ additive in both oils, weld load increases at $0.5 \% \mathrm{w} / \mathrm{v}$ concentration and for $\mathrm{CeO}_{2}$, the weld load was better at 0.25 and $0.5 \% \mathrm{w} / \mathrm{v}$ concentration, respectively. For all PTFE concentrations, the weld load was the same as that for the base oil.

Myshkin et al. [5] compared the tribological behavior of sunflower, corn, rapeseed, olive and linseed oils on a four-ball tester and concluded that their properties correlate with the structure of fatty acids and the activation of unsaturated bonds as a result of the triglycerides oxidation has a positive influence due to tribopolymerization and tribofilm on rubbing surfaces.

Other tribologists tried to use multifunctional additives that could improve a set of characteristics. Zhao [6] reported results on vegetal oils additivated with bio-based multifunctional additives (BMAs), the main objective being the maximization of lubricant oxidation stability by combining bio phenols (gallic acid, caffeic acid and p-hydroxycinnamic acid) with 4-aminodiphenylamine. Also, four ball tests showed that these additives had the antiwear activities better than traditional zinc dialkyl dithiophosphate (ZDDP).

The aim of this study is to evaluate the behavior of rapeseed oil additivated with $1 \%$ wt $\mathrm{TiO}_{2}$ in a severe regime, on a four-ball tester by several tribological parameters as friction coefficient, wear scar diameter, texture parameters.

\section{MATERIALS AND METHODS}

The typical composition of rapeseed oil is (\%): monounsaturated 58, polyunsaturated 33, saturates 9 .

The low erucic rapeseed variety is widely used for applications such as salad dressing, margarines and sauces. The high erucic variety is used in a range of technical purposes, for example bio-degradable lubricating oil as an alternative to mineral oil-based lubricants [2].

In this study, the rapeseed oil has the composition given in Table 1, monosaturated being $62.38 \%$, polyunsaturated $-27.54 \%$ and the saturated $-6.71 \%$.

The test balls are lime polished, made of chrome alloyed steel balls, with $12.7 \pm 0.0005 \mathrm{~mm}$ in diameter, with 64-66 HRC hardness, supplied by SKF. The sample oil volume introduced in the ball cup was $8 \mathrm{ml} \pm 1 \mathrm{ml}$. The test method for investigating the lubricating capacity was that from EN ISO 20623:2017 Petroleum and related products Determination of the extreme-pressure and anti-wear properties of fluids - four ball method [7].

The test parameters for each lubricant were:
- loading force starting from $500 \mathrm{~N}$ till $900 \mathrm{~N}$, is step of $50 \mathrm{~N}( \pm 5 \%)$;

- sliding speed $0.53 \mathrm{~m} / \mathrm{s}$, corresponding to the spindle speeds of the four-ball machine $1400 \mathrm{rpm}( \pm$ $6 \mathrm{rpm})$;

- test time - 1 minute $( \pm 1 \%)$.

Table 1. Typical composition in fatty acids of the rapeseed oil (from Expur Bucharest).

\begin{tabular}{ccc}
\hline Fat acid & Symbol & \%wt \\
\hline Myristic acid & C14:0 & 0.06 \\
Palmitic acid & C16:0 & 4.60 \\
Palmitoleic acid & C16:1 & 0.21 \\
Heptadecanoic acid & C17:0 & 0.07 \\
Heptadecenoic acid & C17:1 & 0.18 \\
Stearic acid & C18:0 & 1.49 \\
Oleic acid & C18:1 & 60.85 \\
Linoleic acid & C18:2 & 19.90 \\
Linolenic acid & C18:3 & 7.64 \\
Arachidic acid & C20:0 & 0.49 \\
Eicosenoic acid & C20:1 & 1.14 \\
others & & 3.37 \\
\hline
\end{tabular}

Lubricants have been inserted into the fixed balls cup to cover these balls. After each test, the ball fastening system and the balls were cleaned and degreased with isopropyl alcohol and ethyl ether, then dried in air stream.

Nanoadditive was supplied by PlasmaChem [8]. The nanopowder of $\mathrm{TiO}_{2}$ (code PL-TiO-P25-HPB) is a mixed rutile/anatase phases and has the following characteristics: obtained by photocatalytic process, the average size of particles was $21 \pm 5 \mathrm{~nm}$, specific surface $50 \pm 10 \mathrm{~m}^{2} / \mathrm{g}$, purity after ignition $>99.5 \%$, ignition loss $<2 \%$; humidity $<1.5 \%$, density $\approx 130$ g/L. Other elements: $\mathrm{Al}_{2} \mathrm{O}_{3}<0.3 \%$ wt., $\mathrm{SiO}_{2}<0.2$ $\%$ wt.

Rapeseed oil additivation was done following the laboratory technology described in Cristea [9], but for soybean oil.

\section{RESULTS AND DISCUSSIONS}

ISO 20623:2017 [6] includes three types of test, test B dealing with wear-load curve, welding load, and initial seizure load, the regime for getting seizure and, finally weld, could be designate as severe.

Figure 1 presents the average values of friction coefficient (COF) during these severe tests (1 minute).

Till $600 \mathrm{~N}$ the additivated oil has COF lower, but after this value, it increases with approx. 0.2 for the range $650 \ldots 900 \mathrm{~N}$. Only at $900 \mathrm{~N}$, the value is near 0.1 meaning a mixt regime and the capability of both lubricants to bear even greater loads as a dry or 
severe mixt contact could give $0.25 \ldots 0.4$. COF is higher for the additivated lubricant very probably because of non-uniform distribution of nano particles on the contact between balls and due to their agglomerations in bigger particles, from nano to micro scale.

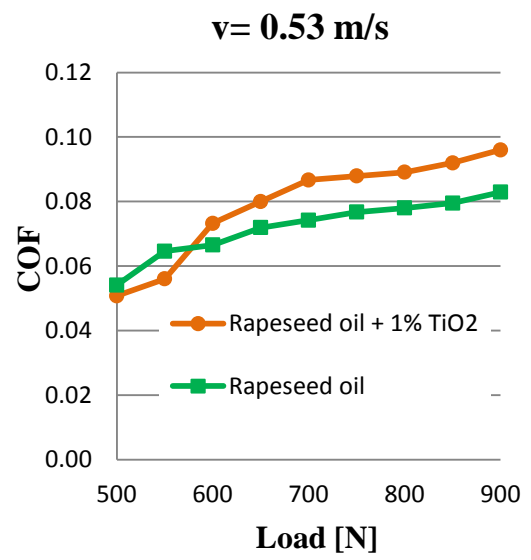

Fig. 1. The average value of COF vs. load
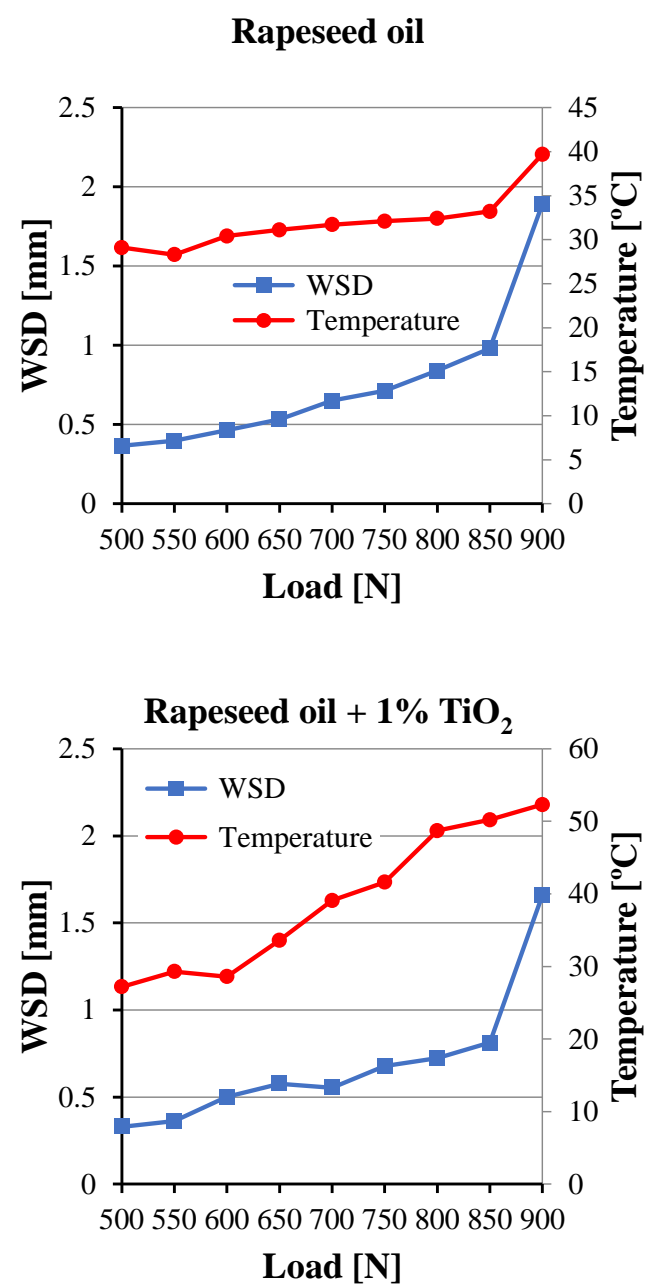

Fig. 2. The evolution of WSD and temperature in the lubricant bath (at the end of the test) vs. load
The following figures present the evolution of two parameters of interest as a function of load.

Figure 2 gives a comparison between wear scar diameter (WSD) and the temperature as measured in the lubricant bath, at the end of the test. WSD is calculated as the average value of six measurements, two on each fixed ball of the tester. For each ball, there were measured the diameter of the contact ellipse in the sliding direction and that perpendicular to it.

For the highest load $(900 \mathrm{~N})$, the temperature is with $12^{\circ} \mathrm{C}$ higher than in the neat rapeseed oil. WSD at the same load is smaller than that for the nonadditivated rapeseed oil: $\mathrm{WSD}_{\text {rapeseed oil }}=1.892 \mathrm{~mm}$ and $\mathrm{WSD}_{\text {rapeseed oil }+1 \% \mathrm{TO} 2}=1.6574 \mathrm{~mm}$.

Comparing data in Fig. 1, one may notice that load-wear curve is lower for the additivated lubricant, especially for higher loads $(800 \ldots 900 \mathrm{~N})$.

Block developed the concept of "flashtemperature" [10] and even subjected to critics, specialist agree that the flash temperature parameter is strongly related to the local temperature flow, generated when two bodies are sliding one against the other, due to friction [11]. FTP, Flash Temperature Parameter, could evidence the regime (including temperature) above which a lubricant is unsecure to work.

Specialized literature offers several relationships for calculating FTP, the authors of this study selected the following [11]:

$$
F T P=\frac{W}{W S D^{1.4}}\left[\mathrm{~N} / \mathrm{mm}^{1.4}\right]
$$

where $W$ is the applied load on the four-ball tester, in $\mathrm{N}$ and $W S D$ is the average diameter of the six diameters, two on each wear scar of the three fixed balls. Thus, FTP is inversely proportional to the WSD, under constant load.

FTP for a lubricant should be interpreted as the lowest temperature for which the fluid could become instable and the consequences could be dangerous (ignition, toxic vapours etc.). High values of FTP recommend a lubricant as the temperature in contact is low enough not evaporate it (and let the contact without lubrication), keeping its viscosity to maintain the fluid film and even the heat evacuation by fluid and not by mixt contact. Low values of this parameter mean that the fluid film is destroyed.

Kalam et al. [12] included FTP in the set of discussed parameters for tests done for a SAE grade 40 lubricant, additivated with amine phosphate as an anti-wear additive, with better results as compared to the non-additivated lubricant, as it reduces coefficient of friction (COF), WSD and TAN value, increases FTP and viscosity. Even a combination of amine phosphate, normal lubricant and palm oil (up to $4 \%$ ) shows better results such as reduces coefficient of friction (COF), WSD and TAN value while, increases FTP and viscosity. 


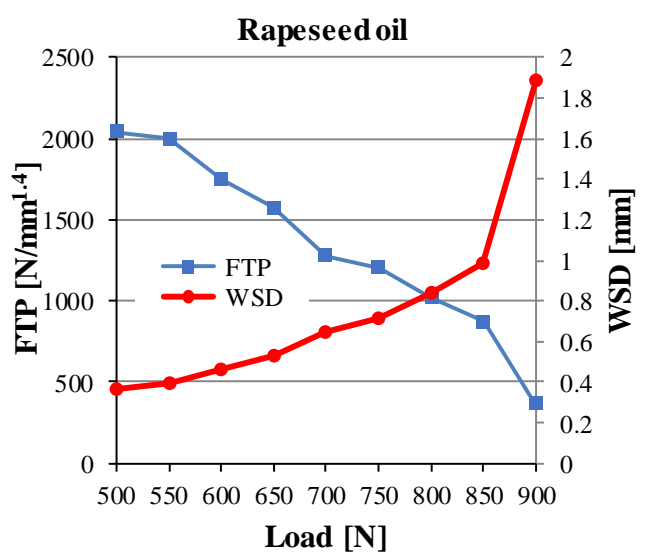

Figure 5 presents the wear scars for the two tested lubricants. One may notice that adding $\mathrm{TiO}_{2}$ in rapeseed oil, the wear scars became smaller.

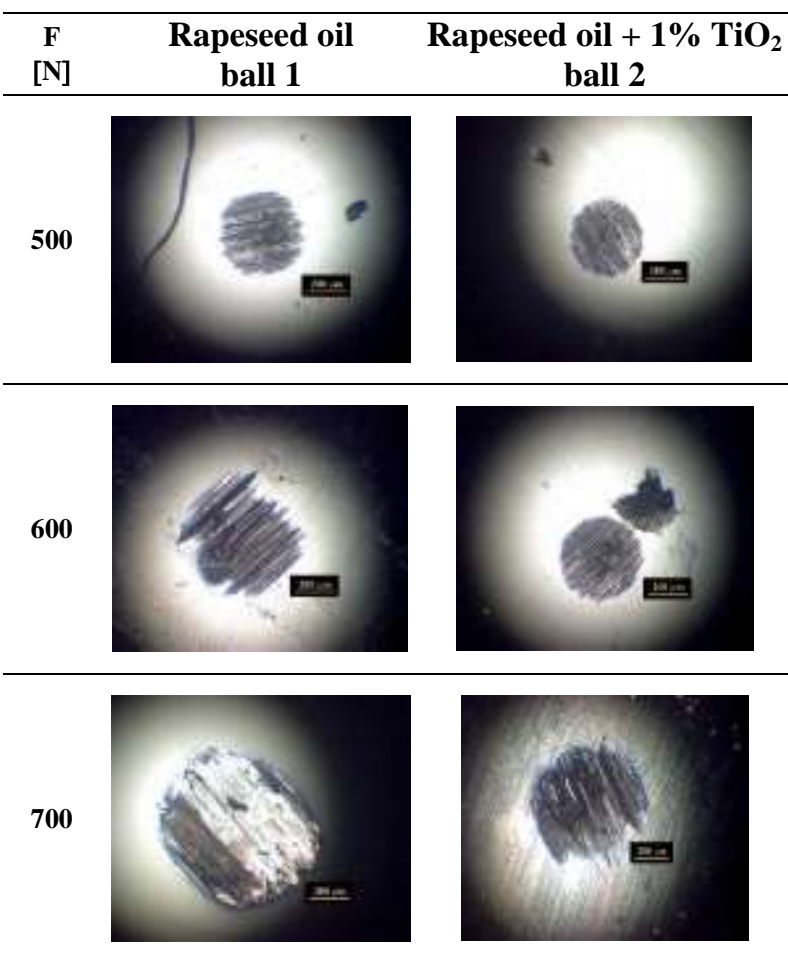

Fig. 3. FTP and WSD vs. load
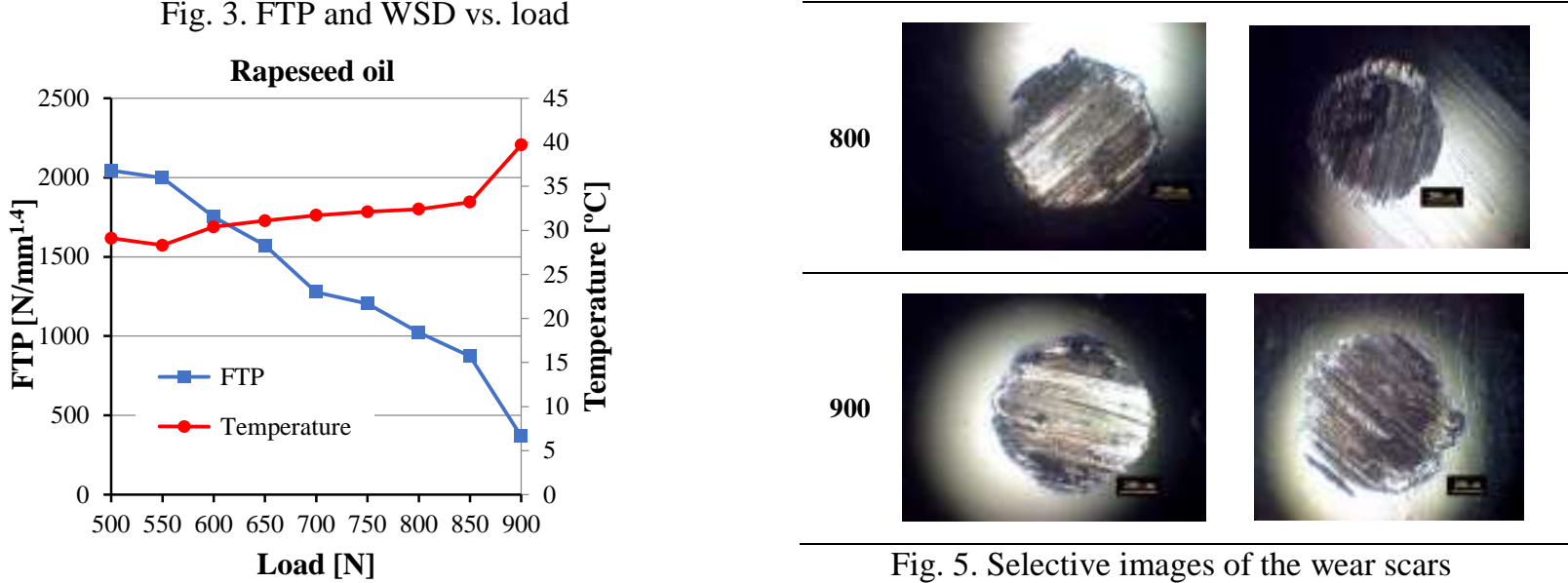

Fig. 5. Selective images of the wear scars

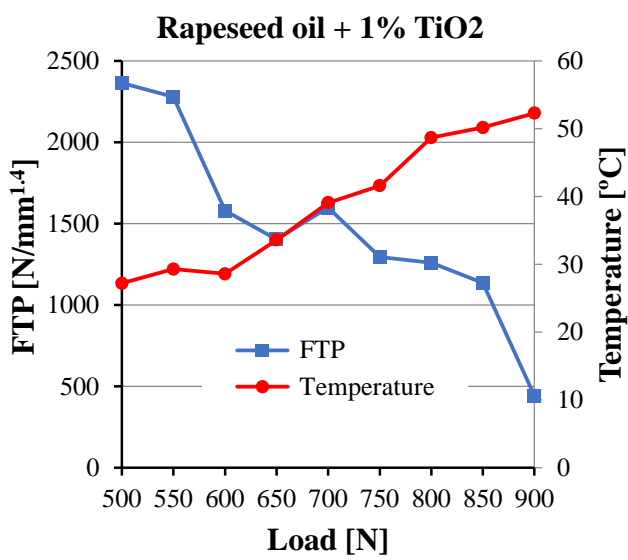

Fig. 4. FTP and temperature in the lubricant bath (at the end of the test) vs. load

Figure 6 presents two texture parameters for the amplitude of the texture, Sa and St, as measured for the entire wear scar and as average for three scars on the fixed balls of one test. The authors selected these two parameters for this study as the first, Sa (the average arithmetic deviation of the profile) is very commonly given in literature, but because it is an averaged parameter, it could not characterize the texture aspect that is important in evaluating the surface in tribological applications. St is the maximum peak-valley height, this parameter being singular, but very important in tribology because this singularity could be "guilty" of destroying the fluid film and initiating direct contact among asperities. Due to modern equipment (NanoFocus $\mu$ Scan, from „Ştefan cel Mare" University, Suceava, Romania), 
the authors investigated all the surface of wear scars and thus, St is relevant for worn surfaces.

They are defined as the height difference between the highest and lowest pixel in the image.

It could be noticed the difference in the trend of each parameter for the rapeseed oil and the rapeseed oil additivated with $1 \% \mathrm{TiO}_{2}$. Recorded texture was generally levelled and then with polynomial levelling, as available in SPIP 6.7.8 [12]. Sa has no big variations depending on load; thus, this parameter is less sensible with load, but St seems to be more dependent on load and on additivation. For neat oil, St is greater than $20 \mu \mathrm{m}$ from $\mathrm{F}=550 \mathrm{~N}$, but for the additivated lubricant, this parameter remains under this value till $700 \mathrm{~N}$. The conclusion of comparing these data is that the additive protects the texture more than the neat oil, but only till $700 \mathrm{~N}$.
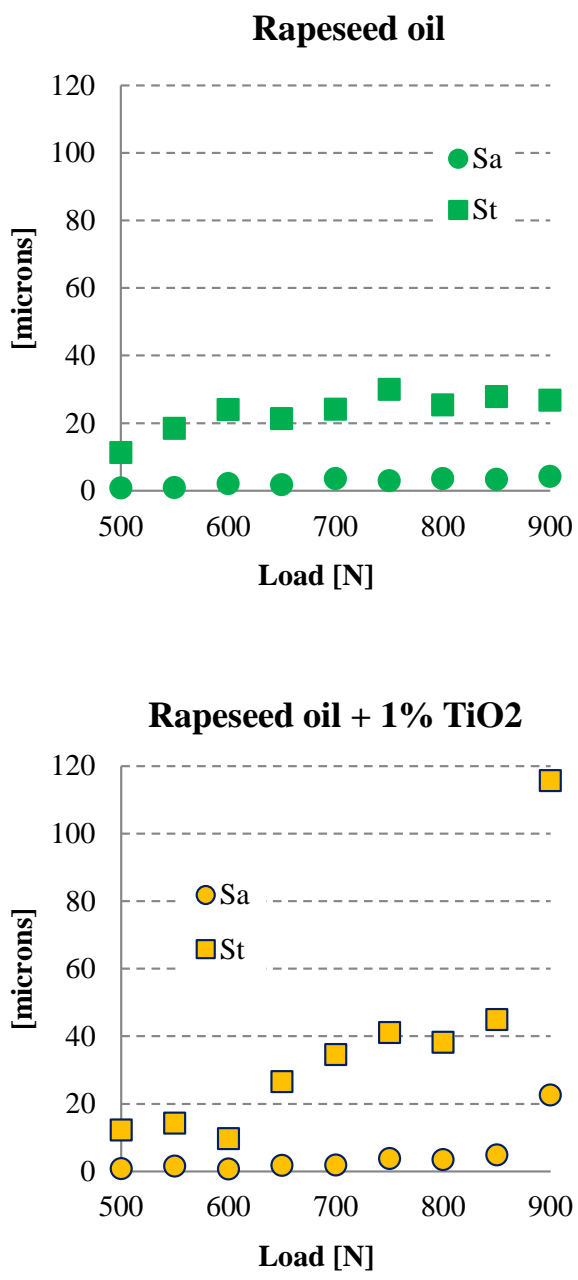

Fig. 6. Two texture parameters, Sa and St vs. load

\section{CONCLUSIONS}

In this paper, the authors reported tribological characteristics for seizure regime of two lubricants: neat rapeseed oil and rapeseed oil additivated with $1 \% \mathrm{TiO}_{2}$. The additive induces a change in the slope of the wear-load curve, meaning in severe regime this additive protect the surfaces.

Till $600 \mathrm{~N}$, the influence of additivation is not obvious, the friction coefficient is lower for the neat oil, WSD is similar, but after this load, the slope for WSD is smaller for the additivated lubricant and for $900 \mathrm{~N}$, this parameter is also smaller. 3D parameters for characterizing the worn surface or the scar reflect in different ways the wear process: $\mathrm{Sa}$ seems to be quite insensitive to the load increase, but other parameters, like St has a significant increase, meaning two processes: additive is pressed on the surface and developed high local peaks or/and the adhesive and abrasive wear is more intense. FTP is almost the same at $900 \mathrm{~N}$, but the additive makes this parameter to evolve with a plateau with low slope, meaning the additivated lubricant has a better behavior under high loads.

\section{AKNOWLEDGEMENT}

This work has been funded by the European Social Fund through the Sectoral Operational Programme Human Capital 2014-2020, "Scholarships for entrepreneurial education among doctoral students and postdoctoral researchers (Be Entrepreneur!)", Contract no. 51680/09.07.2019 SMIS code: 124539.

\section{REFERENCES}

[1] ***Oilseeds and Products Annual EU, AU1704, https://apps.fas.usda.gov/newgainapi/api/report/ downloadreportbyfilename?filename=Oilseeds $\% 20$ and \%20Products\%20Annual_Vienna_EU28_3-31-2017.pdf

[2] *** Rapeseed oil, http://www.neoda.org.uk/rapeseed-oil

[3] Ingole S., Charanpahari A., Kakade A., Umare S. S., Bhatt D. V., Menghani J., 2013, Tribological behavior of nano $\mathrm{TiO}_{2}$ as an additive in base oil, Wear, 301, pp. 776-785

[4] Gupta R. N., Harsha A. P., Singh S., 2018, Tribological study on rapeseed oil with nano- additives in close contact sliding situation, Applied Nanoscience, 8, pp. 567-580.

[5] Myshkin N. K., Grigoriev A.Y., Kavaliova I.N., 2017, Influence of Composition of Plant Oils on Their Tribological Properties, Tribology in Industry, 39(2), pp. 207-210.

[6] Zhao H., Feng J., Zhu J., Yu H., Liu Y., Shi P., Wang S., Liu S., 2020, Synthesis and application of highly efficient multifunctional vegetable oil additives derived from biophenols, Journal of Cleaner Production, 242, 118274

[7] *** EN ISO 20623:2017 Petroleum and related products - Determination of the extremepressure and anti-wear properties of fluids - four ball method. 
[8] *** Nanomaterials and related products, PlasmaChem,

2016 , http://www.plasmachem.com/download/Plasma Chem-General_Catalogue_Nanomaterials.pdf

[9] Cristea G.C., 2017, Tribological characterization of soybean oil additivated with nano materials based on carbon (black carbon, graphite and graphene) (PhD thesis: "Dunarea de Jos" University of Galati).

[10] Blok H., 1963, The flash temperature concept, Wear, 6(6), pp. 483-494.
[11] Marscher W. D., 1982, A critical evaluation of the flash-temperature concept, ASLE Transactions, Tribology, 25(2), pp. 157-174.

[12] Kalam M. A., Masjuki H. H., Shahabuddin M., Mofijur M., 2012, Tribological characteristics of amine phosphate and octylated/butylated diphenylamine additives infused bio-lubricant, Energy Education Science and Technology Part A: Energy Science and Research, 30(1), pp. 123-136.

[12] ***SPIP The Scanning Probe Image Processor SPIPTM, Version 6.7.8 (2019), on-line: http://www.imagemet.com/WebHelp/spip.htm 